\title{
Anisotropic Magnetization Behavior of Electrodeposited Nanocrystalline Ni-Mo Alloy Thin Films and Nanowires Array
}

\author{
T. Ohgai, ${ }^{a, z}$ R. Washio, ${ }^{a, b}$ and Y. Tanaka ${ }^{c}$ \\ ${ }^{a}$ Department of Materials Science and Engineering, Nagasaki University, Nagasaki 852-8521, Japan \\ ${ }^{b}$ Nagoya Aerospace Systems, Mitsubishi Heavy Industries, Ltd. Nagoya 455-8515, Japan \\ ${ }^{c}$ TDK Corporation, Chiba, 272-8558, Japan
}

\begin{abstract}
Nanocrystalline nickel-molybdenum (Ni-Mo) alloy thin films and nanowires array were synthesized in acidic aqueous solution containing citric acid using an induced co-deposition technique. Cross-sectional scanning ion microscope (SIM) images of the electrodeposits revealed that pure $\mathrm{Ni}$ consists of large crystal grains with diameter of several $\mu \mathrm{m}$, while Ni-4.5\% Mo alloy consists of columnar crystals with diameter of several hundred $\mathrm{nm}$ and long axis of the columnar crystals was arrayed vertically to the film plane. On the other hand, no crystal grains were found in Ni-23.6\% Mo alloy which was composed of an amorphous phase. Electrodeposited pure $\mathrm{Ni}$ thin film was hardly magnetized in perpendicular direction to the film plane, while the magnetization of nanocrystalline Ni-11\% Mo alloy thin film reached to saturation at ca. $2.5 \mathrm{kOe}$. On the contrary, Ni nanowires array was easily magnetized in perpendicular direction to the membrane film plane which corresponds to the long axis direction of nanowires, while the nanocrystalline Ni-8.4\% Mo alloy nanowires array was magnetized isotropically in both direction and the soft magnetic property was improved with increasing Mo content in the electrodeposits.

(C) 2012 The Electrochemical Society. [DOI: 10.1149/2.013210jes] All rights reserved.
\end{abstract}

Manuscript submitted May 18, 2012; revised manuscript received July 6, 2012. Published August 29, 2012.

Molybdenum (Mo) has a high melting point $\left(\mathrm{T}_{\mathrm{m}}\right)$ of $2896 \mathrm{~K}$ and is used as an alloying agent in high strength and high corrosion resistance materials such as stainless steels, tool steels, cast irons and high-temperature superalloys. Mo alloys are also used as a catalyst in electrolysis process to produce hydrogen gas from aqueous solution and hydro-desulfurization process to remove sulfur from refined petroleum products. It is very difficult to obtain the bulk alloys containing Mo using a casting method or a deformation processing because of their high $\mathrm{T}_{\mathrm{m}}$ and high strength. On the contrary, it is well known that iron-group metal alloy thin films containing Mo such as Ni-Mo, ${ }^{1}$ $\mathrm{Co}-\mathrm{Mo}^{2}$ and $\mathrm{Ni}-\mathrm{Fe}-\mathrm{Mo}$ alloys ${ }^{3}$ can be electrodeposited from aqueous solution at room temperature and the reduction process is known as induced co-deposition. ${ }^{4}$ Sanches et al. ${ }^{5}$ reported that the electrodeposited Ni-50at.\%Mo alloy thin film with a good electro-catalytic activity for hydrogen evolution reaction and the alloy thin film could be suitable cathode materials for hydrogen production through water electrolysis.

Usually the electrodeposited and electroless-deposited iron-group metal alloy thin films containing Mo consist of small crystals with the diameter of several tens of nanometer. ${ }^{6,7}$ The nanocrystalline irongroup metal alloy thin films are known to show excellent soft magnetic properties, which can be applied to high sensitive magnetic field sensors. Gómez et al. ${ }^{8}$ reported that the coercive force of electrodeposited Co-10at.\% Mo alloy thin film was less than 70 Oe and Co-Mo alloy deposits with Mo content ranging from 5 to $10 \%$ showed an excellent soft-magnetic properties. It is also well known that a magnetic thin film is hardly magnetized in perpendicular direction to the film plane due to the demagnetizing field caused by magnetic poles generated on the film surfaces. ${ }^{9,10}$ On the other hand, a magnetic nanowires array ${ }^{11,12}$ which is assembled in a membrane thin film ${ }^{13}$ is known to be easily magnetized in a perpendicular direction to the film plane. ${ }^{14,15}$

If an iron-group metal alloy nanowires array containing Mo such as $\mathrm{Ni}-\mathrm{Mo}$, Co-Mo and Fe-Mo alloys can be electrodeposited into a membrane filter with numerous nanochannels such as an ion-track etched polycarbonate membrane filter ${ }^{16}$ or an anodized aluminum membrane filter, ${ }^{17}$ a novel catalytic nanowires array with high corrosion resistance and magnetic moment can be synthesized at room temperature. The catalytic nanowires array can be applied to a novel functional device such as a ferromagnetic and catalytic electrode with extremely large specific surface area. For example, in a water electrolysis process, a ferromagnetic and catalytic nanowires array electrode can be easily recovered under certain magnetic field. In this study, Ni-Mo alloy thin films and nanowires array were synthesized using

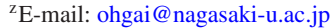

an induced co-deposition technique and their nanocrystalline structures and magnetic properties were investigated for the application of a novel ferromagnetic and catalytic electrode.

\section{Experimental}

Aqueous electrolytic solution was synthesized from nickel sulfate ( $\mathrm{NiSO}_{4} \cdot 6 \mathrm{H}_{2} \mathrm{O}$ ), sodium molybdate $\left(\mathrm{Na}_{2} \mathrm{MoO}_{4} \cdot 2 \mathrm{H}_{2} \mathrm{O}\right)$, iron sulfate $\left(\mathrm{FeSO}_{4} \cdot 7 \mathrm{H}_{2} \mathrm{O}\right)$ and citric acid $\left(\mathrm{C}_{3} \mathrm{H}_{4}(\mathrm{OH})(\mathrm{COOH})_{3}\right)$. The solution $\mathrm{pH}$ was adjusted to 2.0. The solution compositions are shown in Table I. Copper foils $(2 \mathrm{~cm} \times 2 \mathrm{~cm})$ were used as a cathode for electrodepositing Ni-Mo alloy films, while ion track-etched polycarbonate membrane filters with pore-diameter of $100 \mathrm{~nm}$, pore-length of $6 \mu \mathrm{m}$ and pore-density of $6 \times 10^{8}$ pores $\cdot \mathrm{cm}^{-2}$ were used as a nanochannel template for growing Ni-Mo alloy nanowires array. On a surface of the membrane filter, a gold layer was sputter-deposited to cover the pores and make a cathode. A gold wire was used as an anode and $\mathrm{Ag} / \mathrm{AgCl} / \mathrm{KCl}$ sat. electrode was used as a reference electrode. According to a cathodic polarization curve obtained in the preliminary experiment, at around $-0.7 \mathrm{~V}$ (vs. $\mathrm{Ag} / \mathrm{AgCl} / \mathrm{KCl}$ sat.) which was lessnoble than the equilibrium potential of $\mathrm{Ni}^{2+} / \mathrm{Ni}$ and $\mathrm{MoO}_{4}{ }^{2-} / \mathrm{Mo}$, the cathodic current density increased rapidly. Hence, it was estimated that the increase in cathodic current density was mainly caused by the electrodeposition of Ni-Mo alloys. At the potential region less than $-2.0 \mathrm{~V}$, with increasing cathodic current density, the potential polarized significantly to be less-noble region due to the diffusion limit of $\mathrm{Ni}^{2+}$ and $\mathrm{MoO}_{4}{ }^{2-}$ ions. Consequently, the optimum cathode potential for electrodeposition of Ni-Mo alloys was determined to be from $-1.5 \mathrm{~V}$. Ni-Mo alloy thin films and nanowires array were electrodeposited potentio-statically at $-1.5 \mathrm{~V}$ (vs. $\mathrm{Ag} / \mathrm{AgCl} / \mathrm{KCl}$ sat.). Temperature of the electrolytic solution was kept to $313 \mathrm{~K}$. During the electrodeposition of Ni-Mo alloy thin films, the current density was ca. $100 \mathrm{~A} / \mathrm{m}^{2}$ at the cathode potential of $-1.5 \mathrm{~V}$ and the electrodeposition time was kept to $60 \mathrm{~min}$. Therefore, charge for the electrodeposition was estimated to $144 \mathrm{C}$. After growing Ni-Mo alloy nanowires array, the nanochannel templates which were made from ion track-etched polycarbonate membrane filters were dissolved in organic solvent and the remains which were consisted of electrodeposited Ni-Mo alloy nanowires array were served as a sample for SEM observation. To investigate the relationship between $\mathrm{MoO}_{4}{ }^{2-}$ concentration ratio in baths $\left(\mathrm{R}_{\mathrm{Mo}}{ }^{\text {bath }}=100 \times\left[\mathrm{MoO}_{4}{ }^{2-}\right] /\left(\left[\mathrm{MoO}_{4}{ }^{2-}\right]+\left[\mathrm{Ni}^{2+}\right]+\left[\mathrm{Fe}^{2+}\right]\right)\right)$ and Mo content in the alloy deposits $\left(\mathrm{R}_{\mathrm{Mo}}{ }^{\text {depo }}=100 \times[\mathrm{Mo}] /([\mathrm{Mo}]\right.$ $+[\mathrm{Ni}]+[\mathrm{Fe}]))$, the composition of electrodeposits were determined using EDX analysis.

Constituent phase and the crystallinity of the electrodeposits were investigated by using X-ray diffraction (XRD). To observe the 


\begin{tabular}{|c|c|c|c|c|}
\hline \multicolumn{4}{|c|}{$\begin{array}{l}\text { Electrolyte } \\
(\mathrm{mol} / \mathrm{L})\end{array}$} & \multirow{2}{*}{$\begin{array}{c}\mathrm{MoO}_{4}{ }^{2-} \text { concentration } \\
\text { ratio in baths }(\%) \\
\mathrm{R}_{\mathrm{Mo}}{ }^{\text {Bath }}\end{array}$} \\
\hline$\left[\mathrm{MoO}_{4}{ }^{2-}\right]$ & {$\left[\mathrm{Ni}^{2+}\right]$} & {$\left[\mathrm{Fe}^{2+}\right]$} & {$\left[\mathrm{C}_{6} \mathrm{H}_{5} \mathrm{O}_{7}{ }^{3-}\right]$} & \\
\hline 0 & 0.5 & 0 & 0.5 & 0 \\
\hline 0.025 & 0.475 & 0 & 0.5 & 5 \\
\hline 0.05 & 0.45 & 0 & 0.5 & 10 \\
\hline 0.1 & 0.4 & 0 & 0.5 & 20 \\
\hline 0.15 & 0.35 & 0 & 0.5 & 30 \\
\hline 0.2 & 0.3 & 0 & 0.5 & 40 \\
\hline 0.25 & 0.25 & 0 & 0.5 & 50 \\
\hline 0.025 & 0.425 & 0.05 & 0.5 & 5 \\
\hline 0.025 & 0.4 & 0.075 & 0.5 & 5 \\
\hline 0.025 & 0.375 & 0.1 & 0.5 & 5 \\
\hline
\end{tabular}

cross-sectional area of electrodeposited alloy thin films, the samples were cut away and cross-sectionally polished using focused ion beams (FIB). Scanning ion microscope (SIM) was used for observing the cross-sectional structure of nanocrystalline Ni-Mo alloy thin films. Magnetic properties of electrodeposited Ni-Mo alloy thin films and the nanowires array were investigated by using a vibrating sample magnetometer (VSM) with the magnetic field up to $10 \mathrm{kOe}$.

\section{Results and Discussion}

Induced co-deposition process of Ni-Mo alloys. - Figure 1 shows the relationship between $\mathrm{MoO}_{4}{ }^{2-}$ concentration ratio $\left(\mathrm{R}_{\mathrm{Mo}}{ }^{\text {bath }}\right)$ and molybdenum (Mo) content in the alloy deposits $\left(\mathrm{R}_{\mathrm{Mo}}{ }^{\text {depo }}\right)$. With increase in $\mathrm{R}_{\mathrm{Mo}}$ bath, $\mathrm{R}_{\mathrm{Mo}}$ depo also increases. In this figure, composition reference line (C.R.L) means that $\mathrm{R}_{\mathrm{Mo}}{ }^{\text {depo }}$ corresponds to $\mathrm{R}_{\mathrm{Mo}}{ }^{\text {bath }}$. As shown in Fig. 1, in the solution not containing $\mathrm{Fe}^{2+}$ ions, Ni was preferentially deposited besides Mo. For example, Ni-23.6\% Mo alloy deposit $\left(\mathrm{R}_{\mathrm{Mo}}{ }^{\text {depo }}=23.6 \%\right)$ was obtained from the solution containing $50 \%$ of $\mathrm{MoO}_{4}{ }^{2-}$ ions $\left(\mathrm{R}_{\mathrm{Mo}}{ }^{\text {bath }}=50 \%\right)$. $\mathrm{R}_{\mathrm{Mo}}{ }^{\text {depo }}$ was diluted ca. 0.5 times lower than $\mathrm{R}_{\mathrm{Mo}}{ }^{\text {bath. }}$. On the contrary, in the solution containing $\mathrm{Fe}^{2+}$ ions, Mo was preferentially deposited besides Ni. For example, Ni-16\% Mo alloy deposit $\left(\mathrm{R}_{\mathrm{Mo}}{ }^{\text {depo }}=16 \%\right)$ was obtained from the solution containing $5 \%$ of $\mathrm{MoO}_{4}{ }^{2-}\left(\mathrm{R}_{\mathrm{Mo}}{ }^{\text {bath }}=5 \%\right)$. In this condition, $\mathrm{R}_{\mathrm{Mo}}{ }^{\text {depo }}$ was condensed ca. 3 times higher than $\mathrm{R}_{\mathrm{Mo}}{ }^{\text {bath }}$. It is well known that $\mathrm{MoO}_{4}{ }^{2-}$ ions cannot be reduced to the metallic Mo from aqueous solution containing only $\mathrm{MoO}_{4}{ }^{2-}$ ions while they can be reduced to the metallic state from the solution containing $\mathrm{MoO}_{4}{ }^{2-}$ ions in the presence of iron-group metal ions ${ }^{18}$ such as $\mathrm{Ni}^{2+}, \mathrm{Co}^{2+}$ and $\mathrm{Fe}^{2+}$ and ligand such citric acid. ${ }^{19,20}$ This reduction process is known as induced co-deposition ${ }^{4}$ and Fukushima et al..$^{21}$ reported that $\mathrm{MoO}_{4}{ }^{2-}$ ions are reduced by hydrogen atoms adsorbed on the

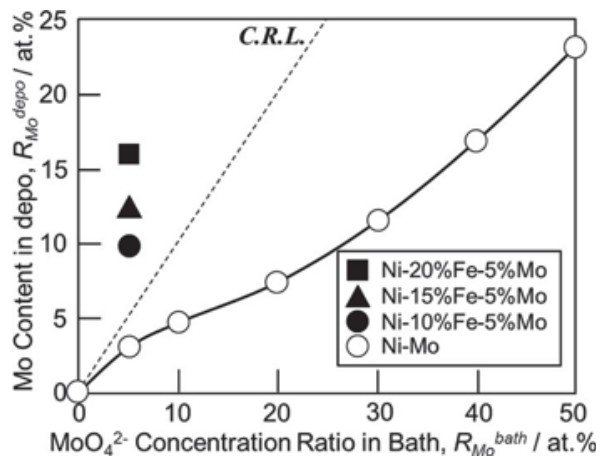

Figure 1. Relationship between $\mathrm{MoO}_{4}{ }^{2-}$ concentration ratio $\left(\mathrm{R}_{\mathrm{Mo}}{ }^{\text {bath }}\right)$ and Mo content in Ni-Mo and Ni-Fe-Mo alloy deposits $\left(\mathrm{R}_{\mathrm{Mo}}{ }^{\text {depo }}\right)$.

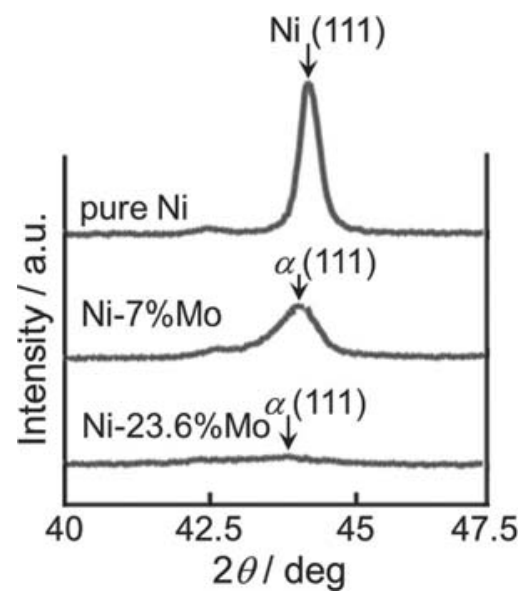

Figure 2. X-ray diffraction profiles of $\mathrm{Ni}$ (111) and $\alpha$ (111) obtained from electrodeposited pure $\mathrm{Ni}, \mathrm{Ni}-7 \% \mathrm{Mo}$ and $\mathrm{Ni}-23.6 \% \mathrm{Mo}$ alloy thin films.

electrodeposited iron-group metals. According to the mechanism, the reduction ability of iron-group metals would depend on the number of unpaired electrons. The number of unpaired $3 \mathrm{~d}$ electrons of $\mathrm{Ni}, \mathrm{Co}$ and $\mathrm{Fe}$ are $0.6,1.6$ and 2.2, respectively. Therefore, the reduction ability of $\mathrm{Fe}$ would be 3.7 times higher than that of Ni. In the present work, the condensation phenomenon of Mo from the solution containing $\mathrm{Fe}^{2+}$ ions into the deposits would be caused by the unpaired $3 \mathrm{~d}$ electrons of co-deposited metallic Fe.

Nanocrystalline structure of electrodeposited Ni-Mo alloys.Figure 2 shows X-ray diffraction profiles of $\mathrm{Ni}$ (111) and $\alpha$ (111) obtained from the electrodeposited pure $\mathrm{Ni}, \mathrm{Ni}-7 \% \mathrm{Mo}$ alloys and $\mathrm{Ni}-23.6 \%$ Mo alloys. The other diffraction peaks such as Ni (200), $\alpha$ (200), Ni (220), $\alpha$ (220), Ni (311) and $\alpha$ (311), which are not shown in the profile, are also observed in the experiment. Preferential orientation of $\mathrm{Ni}$ (111), which is most close-packed crystal plane of $\mathrm{Ni}$, was observed in the diffraction profile obtained from electrodeposited pure Ni. With increasing $\mathrm{R}_{\mathrm{Mo}}{ }^{\text {depo }}$, the diffraction peaks shifted to the lower $2 \theta$ region due to the formation of $\alpha$ phase that is solid solution of Ni-Mo alloys, while the intensities of diffraction peaks due to $\alpha$ (111) were decreased and the shape of peaks has changed to be broad with increasing $\mathrm{R}_{\mathrm{Mo}}{ }^{\text {depo }}$. The other diffraction peaks such as $\alpha(200)$, $\alpha(220)$ and $\alpha(311)$ also showed a similar tendency. These results suggest that the electrodeposited Ni-Mo alloys would be composed of nano-size crystals or amorphous phase. ${ }^{6}$

Figure 3 shows the relationship between Mo contents in the alloy deposits $\left(\mathrm{R}_{\mathrm{Mo}}{ }^{\text {depo }}\right)$ and the lattice constants of $\alpha$ phase $\left(\mathrm{a}_{\mathrm{Ni}-\mathrm{Mo}}\right)$. With increase in $\mathrm{R}_{\mathrm{Mo}}{ }^{\text {depo }}$, $\mathrm{a}_{\mathrm{Ni}-\mathrm{Mo}}$ also increases linearly up to ca. $12 \%$ of $\mathrm{R}_{\mathrm{Mo}}{ }^{\text {depo }}$. It is well known that Mo forms a stable bec crystal phase while Ni has an fcc structure. The lattice constants of Ni and Mo are $0.352 \mathrm{~nm}$ and $0.315 \mathrm{~nm}$ while atomic radii of them are $0.124 \mathrm{~nm}$ and

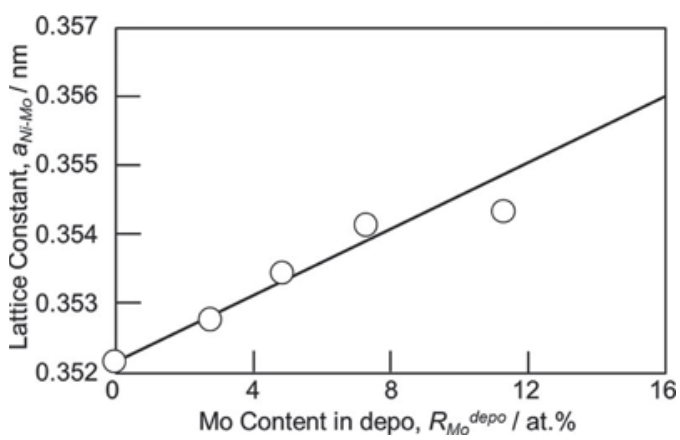

Figure 3. Relationship between Mo contents in Ni-Mo alloy deposits $\left(\mathrm{R}_{\mathrm{Mo}}{ }^{\text {depo }}\right)$ and the lattice constants $\left(\mathrm{a}_{\mathrm{Ni}-\mathrm{Mo}}\right)$. 


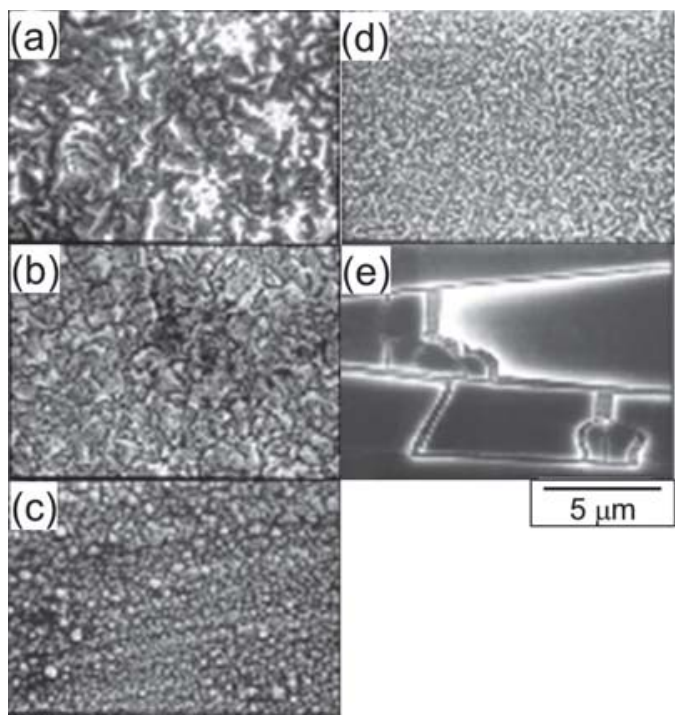

Figure 4. SEM images of electrodeposited $\mathrm{Ni}(\mathrm{a}), \mathrm{Ni}-4.5 \% \mathrm{Mo}$ alloy (b), Ni$6 \%$ Mo alloy (c), Ni-19\% Mo alloy (d) and Ni-23.6\% Mo alloy (e).

$0.139 \mathrm{~nm}$, respectively. According to the binary phase diagram ${ }^{22}$ of $\mathrm{Ni}-\mathrm{Mo}$, the alloy forms an fcc substitutional solid solution $\alpha$ phase ranging up to ca. $10 \%$ of $\mathrm{R}_{\mathrm{Mo}}{ }^{\text {depo }}$. Donten et al. ${ }^{23}$ also reported that the distance of $\alpha$ (111) lattice plane increases linearly in the range of Mo content up to 15 at.\%. Such a phenomenon is typical for the formation of a binary solid solution phase which is composed of the matrix metal with small atomic radius and the solute metal with large atomic radius. Therefore, the results obtained in this work suggest that Mo in the electrodeposits exist as metallic solute in the fcc substitutional solid solution phase of Ni-Mo alloy.

SEM images of electrodeposited $\mathrm{Ni}$ (a), Ni-4.5\% Mo alloy (b), Ni-6\%Mo alloy (c), Ni-19\%Mo alloy (d) and Ni-23.6\%Mo alloy (e) are shown in Fig. 4. The average crystal grains size of electrodeposited $\mathrm{Ni}-19 \%$ Mo alloy (Fig. 4d) is apparently smaller than that of pure $\mathrm{Ni}$ (Fig. 4a). On the other hand, no crystal grains and several cracks have been found in SEM image of Ni-23.6\% Mo alloy as shown in Fig. 4e. As shown in Fig. 2, the shape of peaks has changed to be broad with increasing $\mathrm{R}_{\mathrm{Mo}}$ depo. According to the binary phase diagram $^{22}$ of $\mathrm{Ni}-\mathrm{Mo}$, the alloy forms an intermetallic phase $\left(\mathrm{Ni}_{4} \mathrm{Mo}\right)$ at $20 \%$ of $\mathrm{R}_{\mathrm{Mo}}{ }^{\text {depo }}$. Donten et al. ${ }^{23}$ reported that the amorphous or nanocrystalline structure appears for the deposits of Mo content higher than ca. 20\%. They also suggested that the transformation of the solid solution of Mo in $\mathrm{Ni}$ into either the deformed structure of $\mathrm{Ni}_{4} \mathrm{Mo}$ or a mixture of the saturated Ni-Mo solid solution with nanostructured Ni takes place at the Mo content higher than ca. 20\%. Therefore, the cracks seem to be caused by the formation of a hard phase such as amorphous $\mathrm{Ni}_{4} \mathrm{Mo}$. Consequently, these results suggest that the electrodeposited Ni-Mo alloys containing less than $19 \%$ of Mo consist of nanocrystalline phase while the alloys containing more than $20 \%$ of Mo consist of amorphous phase.

Figure 5 shows the cross-sectional SIM images of electrodeposited $\mathrm{Ni}$ (a), Ni-4.5\%Mo alloy (b) and Ni-23.6\% Mo alloy (c). Electrodeposited $\mathrm{Ni}$ consists of large crystal grains with the diameter of several $\mu \mathrm{m}$ as shown in Fig. 5a, while Ni-4.5\% Mo alloy consists of columnar crystals with the diameter of several hundred $\mathrm{nm}$ and the long axis of the columnar crystals was arrayed vertically to the film plane as shown in Fig. 5b. On the other hand, no crystal grains have been found in the cross-sectional SIM image of Ni-23.6\% Mo alloy as shown in Fig. 5c. With increasing $R_{\text {Mo }}{ }^{\text {depo }}$, the film thickness was decreased. The film thicknesses of electrodeposited $\mathrm{Ni}, \mathrm{Ni}-4.5 \%$ Mo alloy and $\mathrm{Ni}-23.6 \%$ Mo alloy were around $10 \mu \mathrm{m}, 5 \mu \mathrm{m}$ and $2 \mu \mathrm{m}$. During the electrodeposition, the current density was ca. $100 \mathrm{~A} / \mathrm{m}^{2}$ and the electrodeposition time was kept to $60 \mathrm{~min}$. Therefore, the current efficiency for $\mathrm{Ni}, \mathrm{Ni}-4.5 \% \mathrm{Mo}$ and $\mathrm{Ni}-23.6 \% \mathrm{Mo}$ alloy deposition were

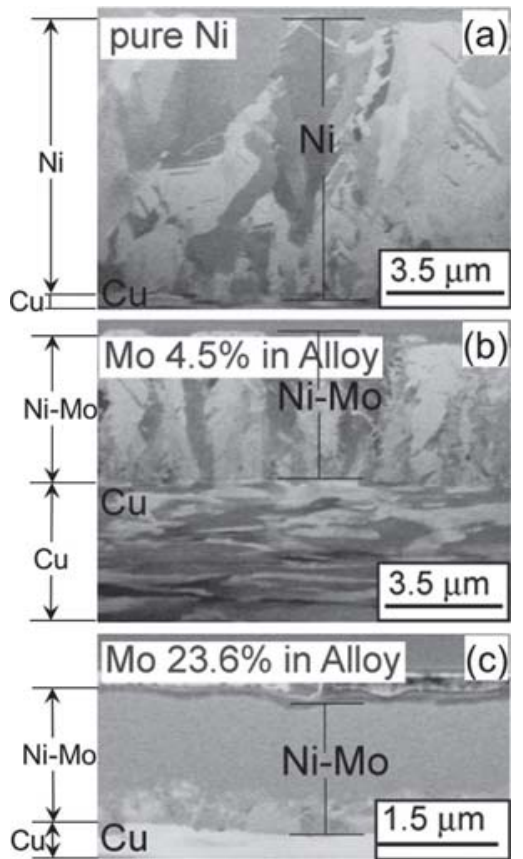

Figure 5. Cross-sectional SIM images of electrodeposited Ni (a), Ni-4.5\%Mo alloy (b) and Ni-23.6\% Mo alloy (c).

estimated to ca. $81.3 \%, 43.4 \%$ and $21.6 \%$. It has been known that the decreasing of current efficiency for induced co-deposition process is also observed in Ni-W binary alloys system as well as Ni-Mo alloys. Gileadi et al. ${ }^{24}$ reported that the induced co-deposition behavior of $\mathrm{Ni}$ $\mathrm{W}$ alloys from the electrolytic solution not containing ammonia. In the report, they have found that the current efficiency for the alloy deposition decreases with increasing $\mathrm{W}$ content in the alloy. Therefore, it is suggested that the decreasing of current efficiency for electrodeposition of Ni-Mo alloys in the present work would be caused by the catalytic effect ${ }^{21}$ of electrodeposited Ni-Mo alloys for the reduction of hydrogen ions.

Anisotropic magnetization behavior of electrodeposited Ni-Mo alloy thin films. - Fig. 6 shows the magnetization curves of electrodeposited Ni thin film (Fig. 6a), Ni-11\%Mo alloy thin film (Fig. 6b) and Ni-10\%Mo-12\%Fe alloy thin film (Fig. 6c) are shown in. Magnetic field was applied to in-plane (dashed line) and perpendicular (solid line) direction to the film plane. As shown in Fig. 6a, Ni thin film was hardly magnetized in perpendicular direction due to the extremely large demagnetizing field $\left(\mathrm{H}_{\mathrm{d}}\right)$ caused by the inverse magnetic poles generated on the film surfaces. The effective magnetic field $\left(\mathrm{H}_{\text {eff }}\right)$ can be expressed by the following equation.

$$
\mathrm{H}_{\text {eff }}=\mathrm{H}_{\mathrm{a}}-\mathrm{H}_{\mathrm{d}}=\mathrm{H}_{\mathrm{a}}-\mathrm{f}_{\mathrm{d}} \cdot \mathrm{M} / \mu_{0}
$$

Here, $H_{a}$ is the applied magnetic field, $f_{d}$ is the marerials shape factor in demagnetizing field, $M$ is magnetic moment and $\mu_{0}$ is peameability constant. When the magnetic field is applied to perpendicular direction to the film plane, $f_{d}$ will be maximum value, hence $H_{\text {eff }}$ will be minimum value. On the contrary, Ni thin film was easily magnetized in in-plan direction $\left(f_{d}=0\right)$ and the magnetization reached to saturation at less than $1 \mathrm{kOe}$. Coercive force $\left(\mathrm{H}_{\mathrm{c}}\right)$ of $\mathrm{Ni}$ thin film was ca. $100 \mathrm{Oe}$. On the other hand, magnetization of Ni-11\% Mo alloy thin film reached to saturation at ca. $2.5 \mathrm{kOe}$ even in perpendicular direction as shown in Fig. 6b. This is resulting from decreasing $\mathrm{H}_{\mathrm{d}}$ due to increasing the content of non-magnetic Mo component because $\mathrm{H}_{\mathrm{d}}$ caused by the inverse magnetic poles depends on $\mathrm{M}$. $\mathrm{H}_{\mathrm{c}}$ of Ni-11\% Mo alloy thin film was ca. $10 \mathrm{Oe}$ (Fig. 6b), while that of Ni-10\%Mo- $12 \% \mathrm{Fe}$ alloy thin film was around 1 Oe (Fig. 6c). This improvement of soft magnetic property in $\mathrm{Ni}-10 \% \mathrm{Mo}-12 \% \mathrm{Fe}$ alloy would be introduced 


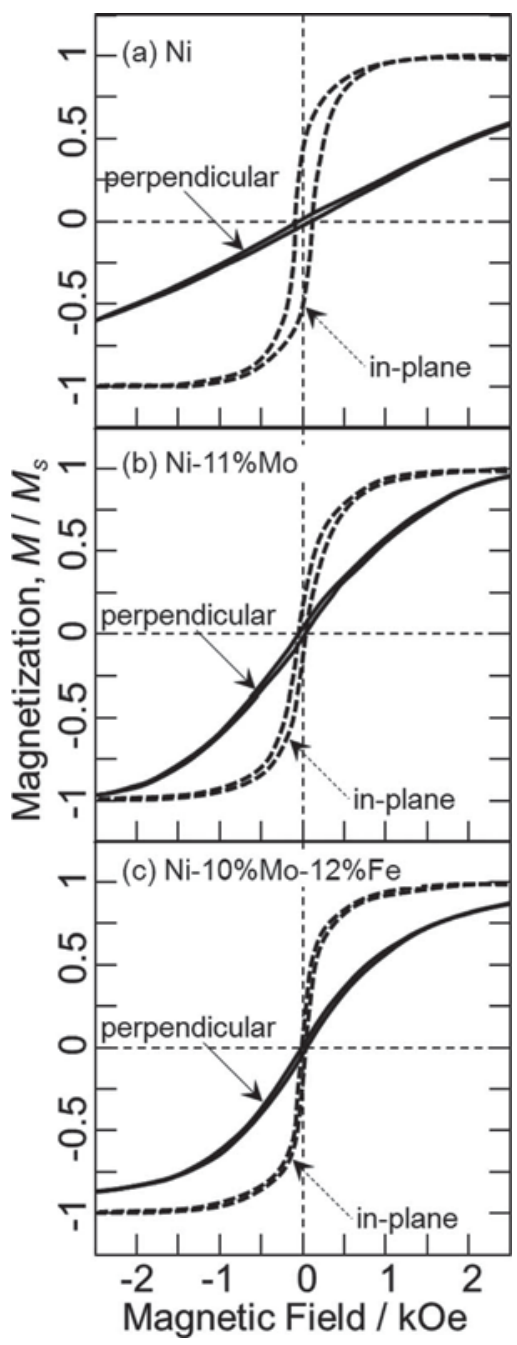

Figure 6. Magnetization curves of electrodeposited $\mathrm{Ni}$ (a), Ni-11\% Mo (b) and $\mathrm{Ni}-10 \% \mathrm{Mo}-12 \% \mathrm{Fe}(\mathrm{c})$. Magnetic field was applied to in-plane and perpendicular direction to the film plane.

by decreasing the crystal grain size $\left(\mathrm{D}_{\mathrm{c}}\right)$ due to the co-deposition of Mo and decreasing the magneto crystalline anisotropy due to codeposition of $\mathrm{Fe}$ in fec Ni alloy matrix. Gómez et al. ${ }^{25}$ reported that $\mathrm{H}_{\mathrm{c}}$ of electrodeposited Co-23at.\%Mo alloy thin film was less than $100 \mathrm{Oe}$ and Co-Mo alloy deposits with Mo content ranging from 20 to $23 \%$ showed an excellent soft-magnetic behavior. Tanase et al. ${ }^{26}$ reported that $\mathrm{H}_{\mathrm{c}}$ of electrodeposited Co-Ni-25.4at.\%Mo alloy thin film was ca. 350 Oe. It is well known that the anisotropy field of hcp-Co $\left(\mathrm{H}_{\mathrm{k}}\right.$ $=7400 \mathrm{Oe})$ is larger than that of fcc-Ni $\left(\mathrm{H}_{\mathrm{k}}=184 \mathrm{Oe}\right)$ due to the asymmetry of crystal structure. Therefore, $\mathrm{H}_{\mathrm{c}}$ of Co alloys would be much larger than that of $\mathrm{Ni}$ alloys obtained in the present work. As shown in Fig. 6, with increase in $\mathrm{R}_{\mathrm{Mo}}{ }^{\text {depo }}, \mathrm{H}_{\mathrm{c}}$ decreased. By the way, $\mathrm{D}_{\mathrm{c}}$ of Ni-Mo alloys decreased with increase in $\mathrm{R}_{\mathrm{Mo}}{ }^{\text {depo }}$ as shown in Fig. 2, Fig. 4 and Fig. 5. Herzer et al. ${ }^{27}$ reported that $\mathrm{H}_{\mathrm{c}}$ decreases with decreasing $D_{c}$ in the range of $D_{c}$ than ca. $50 \mathrm{~nm}$. Therefore, it is suggested that $\mathrm{H}_{\mathrm{c}}$ of electrodeposited Ni-Mo alloys decreased due to decreasing in $\mathrm{D}_{\mathrm{c}}$ of the deposits.

Structure and magnetic properties of electrodeposited Ni-Mo alloy nanowires array.-Figure 7 shows SEM image of electrodeposited Ni-8.4\% Mo alloy nanowires array separated from a polycarbonate membrane filter. Diameter and length of the nanowires corresponds well to that of nanochannels and the cylindrical shape of nanowires was perfectly transferred from that of nanochannels. Aspect ratio of the nanowires can reach to ca. 60 . The length of nanowires can be
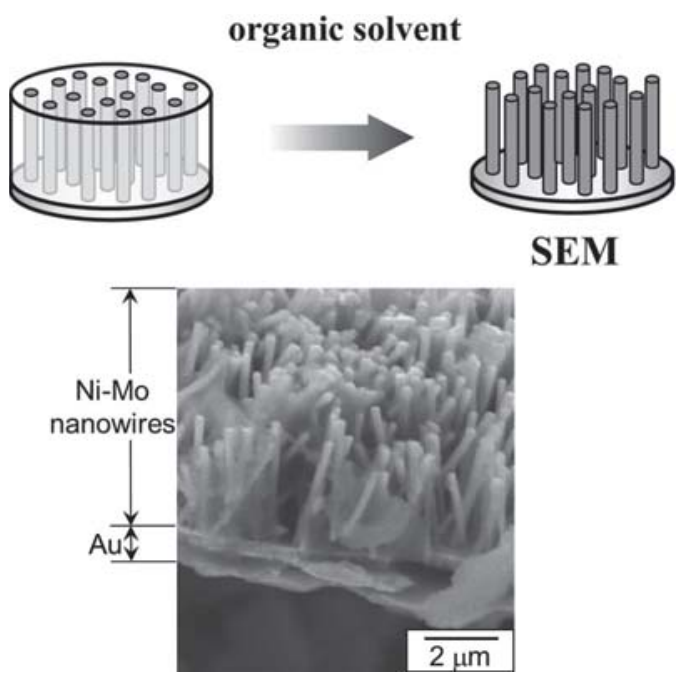

Figure 7. SEM image of electrodeposited Ni-8.4\% Mo alloy nanowires array separated from a polycarbonate membrane filter.

ranged up to $6 \mu \mathrm{m}$ by controlling deposition time, while the diameter of nanowires is fixed to around $100 \mathrm{~nm}$. The density of nanowires array was ca. $6 \mu \mathrm{m}^{-2}$. Lateral area of a nanowire is estimated to be around $2 \mu \mathrm{m}^{2}$. Therefore, surface area of the nanowires array is estimated to be around 13 times larger than that of thin film.

Figure 8 shows magnetization curves of electrodeposited $\mathrm{Ni}$ nanowires array (Fig. 8a) and $\mathrm{Ni}-8.4 \%$ Mo alloy nanowires array (Fig. 8b). Magnetic field was applied to in-plane (dashed line) and perpendicular (solid line) direction to the membrane film plane. The perpendicular direction to the membrane film plane corresponds to the parallel direction to the long axis of nanowires. As shown in Fig. 8a, Ni nanowires array was easily magnetized even in perpendicular direction due to the extremely small demagnetizing field caused by the small

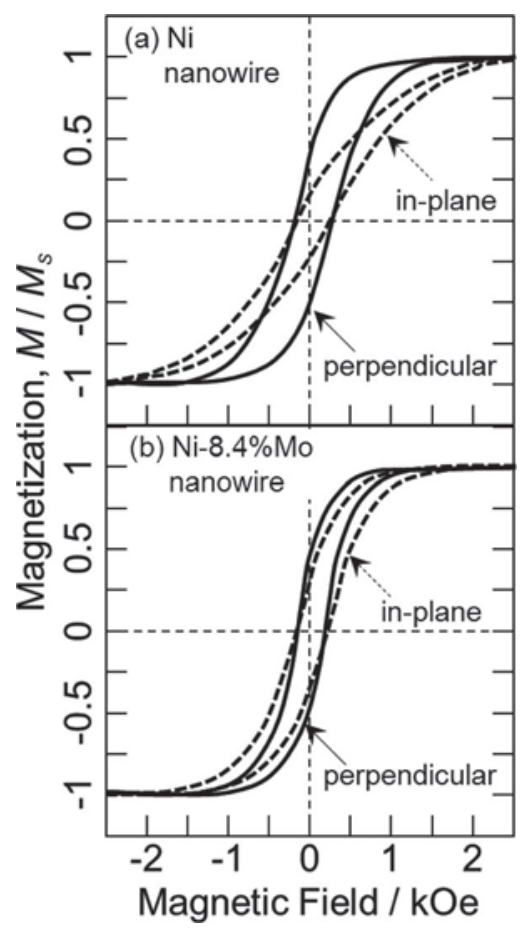

Figure 8. Magnetization curves of electrodeposited Ni nanowires array (a) and $\mathrm{Ni}-8.4 \%$ Mo alloy nanowires array (b). Magnetic field was applied to in-plane and perpendicular direction to the membrane film plane. 
density of magnetic poles generated on the edge of nanowires. ${ }^{28,29}$ $\mathrm{H}_{\mathrm{c}}$ of $\mathrm{Ni}$ nanowires was ca. $0.2 \mathrm{kOe}$. On the contrary, as shown in Fig. 8 b, Ni-8.4\%Mo alloy nanowires array was isotropically magnetized in the both direction. This is resulting from decreasing $\mathrm{H}_{\mathrm{d}}$ due to the small density of magnetic poles generated on the edge of $\mathrm{Ni}$-Mo alloy nanowires and increasing the content of non-magnetic Mo component.

\section{Conclusions}

With increase in $\mathrm{MoO}_{4}{ }^{2-}$ concentration ratio in baths $\left(\mathrm{R}_{\mathrm{Mo}}{ }^{\text {bath }}\right)$ up to $50 \%$, Mo content in the Ni-Mo alloy deposits $\left(\mathrm{R}_{\mathrm{Mo}}{ }^{\text {depo }}\right)$ increased up to $23.6 \%$, while the current efficiency for the alloy deposition decreased down to $21.6 \%$. It was suggested that the electrodeposited Ni-Mo alloy acted as a catalyst for hydrogen evolution during the induced co-deposition process. The average crystal grain size $\left(D_{c}\right)$ of electrodeposited Ni-Mo alloys decreased down to several tens of nanometers with increasing $\mathrm{R}_{\mathrm{Mo}}{ }^{\text {depo }}$ up to $19 \%$, while an amorphous phase was observed in the alloy deposits with $\mathrm{R}_{\mathrm{Mo}}{ }^{\text {depo }}$ of $23.6 \%$. It was estimated that Mo in the alloy deposits existed as metalic solute in an fcc substitutional solid solution phase and suppressed the crystal growth of Ni-Mo alloy. Coercive force $\left(\mathrm{H}_{\mathrm{c}}\right)$ of electrodeposited Ni-Mo alloys decreased with increase in $\mathrm{R}_{\mathrm{Mo}}{ }^{\text {depo }}$ and decrease in $\mathrm{D}_{\mathrm{c}} . \mathrm{H}_{\mathrm{c}}$ of $\mathrm{Ni}-10 \% \mathrm{Mo}-12 \% \mathrm{Fe}$ alloy thin film was ca. $1 \mathrm{Oe}$, which is quite smaller than that of Ni-Mo alloys. It was concluded that the improvement of soft magnetic property in Ni-Mo-Fe alloy was caused by decreasing $D_{c}$ due to the co-deposition of Mo and decreasing the magneto crystalline anisotropy due to co-deposition of Fe in fcc Ni alloy matrix. Ni$8.4 \% \mathrm{Mo}$ alloy nanowires array were isotropically magnetized and the soft magnetic properties were improved with increasing $\mathrm{R}_{\mathrm{Mo}}{ }_{\text {depo }}$ and decrease in $D_{c}$. It was found that the Ni-Mo alloy nanowires array synthesized in the present work has a potential capability as a novel ferromagnetic and catalytic electrode with large specific surface area.

\section{Acknowledgments}

This work was supported in part by TDK Corporation, Mitutoyo Association for Science \& Technology, Yazaki Memorial Foundation for Science \& Technology, Research Foundation for Materials Sci- ence, Japan Society for the Promotion of Science (Grant-in-aid for Scientific Research C : No.19560734).

\section{References}

1. E. J. Podlaha, M. Matlosz, and D. Landolt, J. Electrochem. Soc., 140, L149 (1993). 2. E. J. Podlaha and D. Landolt, J. Electrochem. Soc., 144, 1672 (1997).

3. Q. Zhou, P. J. Heard, and W. Schwarzacher, J. Appl. Phys., 109, 054313 (2011)

4. A. Brenner, Electrodeposition of Alloys, Academic Press, New York, London (1963)

5. L. S. Sanches, S. H. Domingues, C. E. B. Marino, and L. H. Mascaro, Electrochem. Commun., 6, 543 (2004)

6. E. Beltowska-Lehman and P. Indyka, Thin Solid Films, 520, 2046 (2012).

7. I. Koiwa, M. Usuda, K. Yamada, and T. Osaka, J. Electrochem. Soc., 135, 718 (1988).

8. E. Gómez, E. Pellicer, and E. Vallés, Electrochem. Commun., 6, 853 (2004).

9. T. Osaka, N. Kasai, and I. Koiwa, J. Electrochem. Soc., 130, 568 (1983).

10. J. Horkans, D. J. Seagle, and I. C. H. Chang, J. Electrochem. Soc., 137, 2056 (1990).

11. J. Verbeeck, O. I. Lebedev, G. V. Tendeloo, L. Cagnon, C. Bougerol, and G. Tourillon, J. Electrochem. Soc., 150, E468 (2003).

12. S. Z. Chu, S. Inoue, K. Wada, Y. Kanke, and K. Kurashima, J. Electrochem. Soc., 152, C42 (2005).

13. T. Ohgai, K. Hjort, R. Spohr, and R. Neumann, J. Appl. Electrochem., 38, 713 (2008).

14. S. Anandakumar, V. S. Rani, T. S. Ramulu, H. Yang, B. H. Lim, J. Kim, S. S. Yoon, and C. G. Kim, J. Electrochem. Soc., 158, E124 (2011).

15. M. D. L. Balela, S. Yagi, and E. Matsubara, J. Electrochem. Soc., 158, D210 (2011)

16. R. Spohr, C. Zet, B. E. Fischer, H. Kiesewetter, P. Apel, I. Gunko, T. Ohgai, and L. Westerberg, Nucl. Inst. Meth. Phys. Res. B, 268, 676 (2010).

17. H. Masuda and F. Hasegwa, J. Electrochem. Soc., 144, L127 (1997)

18. E. Chassaing, K. Vu Quang, and R. Wiart, J. Appl. Electrochem., 19, 839 (1989).

19. E. Uekawa, K. Murase, E. Matsubara, T. Hirato, and Y. Awakura, J. Electrochem. Soc., 145, 523 (1998)

20. K. Murase, H. Ando, E. Matsubara, T. Hirato, and Y. Awakura, J. Electrochem. Soc., 147, $2210(2000)$

21. H. Fukushima, T. Akiyama, S. Akagi, and K. Higashi, Trans. Jpn. Inst. Met., 20, 358 (1979).

22. H. Okamoto, J. Phase Equil., 12, 703 (1991).

23. M. Donten, H. Cesiulis, and Z. Stojek, Electrochim. Acta, 50, 1405 (2005).

24. O. Y. Metzler, L. Zhu, and E. Gileadi, Electrochim. Acta, 48, 2551 (2003).

25. E. Gómez, E. Pellicer, X. Alcobé, and E. Vallés, J. Solid State Electrochem., 8, 497 (2004).

26. S. I. Tanase, D. P. Tanase, M. Dobromir, and V. Georgescu, Appl. Surf. Sci., 257, 10903 (2011).

27. A. Hernando, P. Marin, M. Vazquez, J. M. Barandiaran, and G. Herzer, Phys. Rev. B, 58, 366 (1998)

28. L. Sun, P. C. Searson, and C. L. Chien, Appl. Phys. Lett., 74, 2803 (1999).

29. T. Ohgai, I. Enculescu, C. Zet, L. Westerberg, K. Hjort, R. Spohr, and R. Neumann, J. Appl. Electrochem., 36, 1157 (2006). 